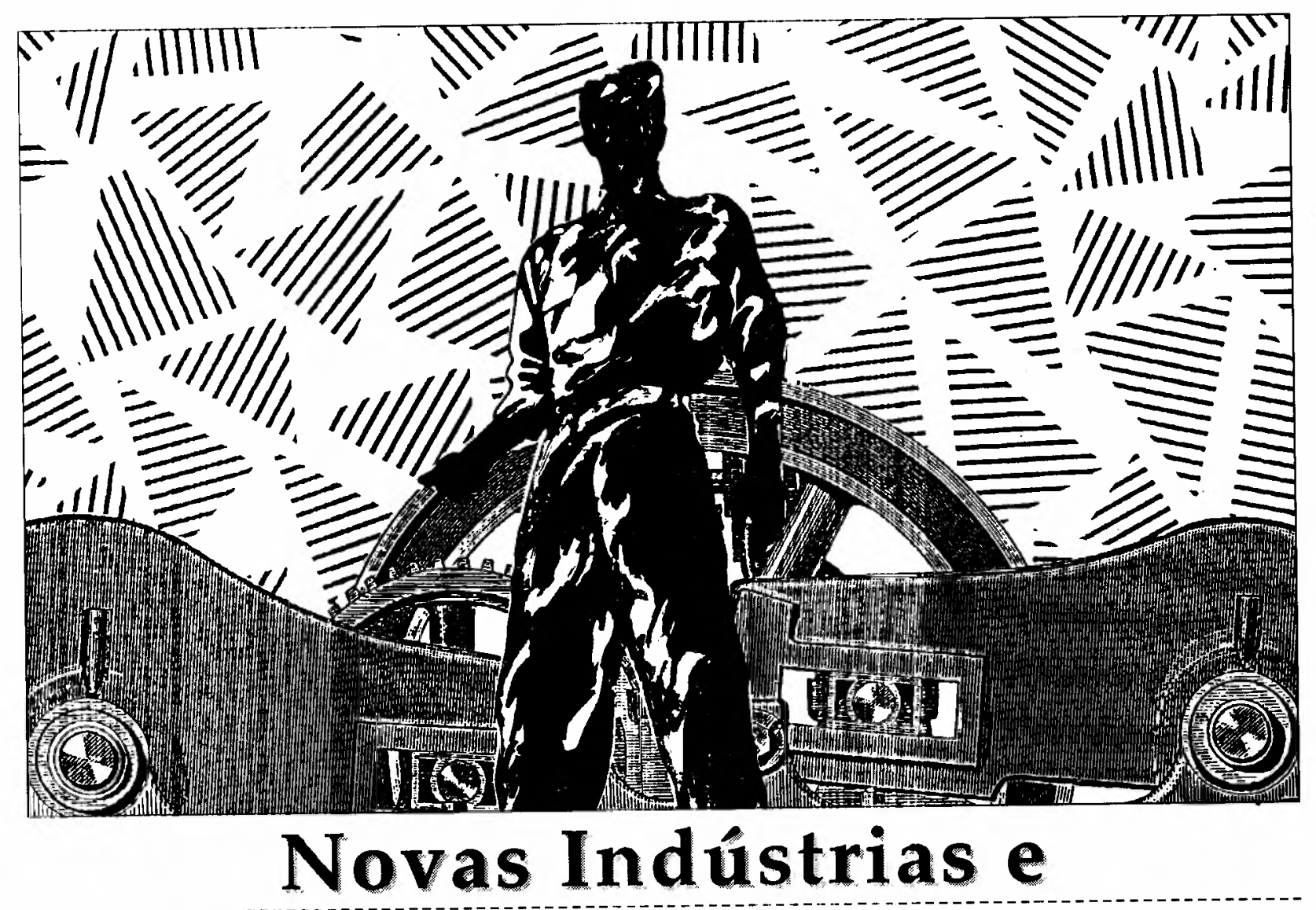

\title{
Desenvolvimento Tecnológico
}

\section{INDIANA PINHEIRO DA F. RODRIGUES}

Professora Adjunta do Departamento de Ciências Administrativas da Faculdade de Ciências Econômicas da UFMG.

\section{ABIGAIL DE OLIVEIRA CARVALHO}

Professora Adjunta do Departamento de Ciências Administrativas da Faculdade de Ciências Econômicas da UFMG.

RESUMO:Este texto ac'alia opotencial da nova geração de impresírios para transformarem-se em agentes catalisadores no esforço de desenvolvimento tecnológico. Analisa amostra de empresários no Estado de Minas Gernis, a partir de entrevistas, buscando dados objetivos referentes à organização da empresa e dados subjetioos referentes à percepção desses empresários sobre a organização e o ambiente. Mudanças na ordem econômica mundial nesta última década do século não podem ser entendidas como um processo linear e impõem mudanças nas três dimensões: econôrnica, social e política. O domínio do conhecimento científico e tecnológico aparece como recurso crítico a ser alcançado por ação consciente e determinada dos agentes sociais. A meta nāo pode ser alcançar os países desenvolvidos, mas o desenvolvimento auto-sustentável, adequado às condiçōes e recursos humanos de cada país.

PALAVRAS-CHAVE: Desenvolvimento tecnológico, empresário, tecnologia, ambiente, novos negócios.

\section{INTRODUÇÃO}

O sucesso material aliado à estabilidade política e social dos países industrializados transformou em mito a idéia de que o caminho do progresso, para os países do Terceiro Mundo, estava em seguir os passos daqueles países, queimando etapas no processo de industrialização até atingir o nível de desenvolvimento econômico do Primeiro Mundo. Por outro lado, pensa-se a sociedade pós-industrial como decorrência natural do processo evolutivo do capitalis- 
mo, na qual a atividade dominante não estará mais no setor industrial e sim no setor de serviços. A lógica parece razóavel considerando que passamos de uma sociedade agrária para a sociedade industrial e que ao lado do crescimento do setor de serviços ocorre um declínio do setor industrial nos países desenvolvidos ${ }^{1}$. No entanto, a história não acontece de forma tão linear e não podemos esquecer que a mudança da sociedade agrária para a sociedade industrial não foi uma mudança apenas no plano econômico, mas, também, nos planos social e político. Não nos parece relevante, aqui, o argumento do determinismo econômico, mas a constatação de que mudanças estruturais envolvem as três dimensões - econômica, social e política - e não podem ser entendidas como processo evolutivo linear ${ }^{2}$. Os sinais de mudança neste final de século incitam à reflexão para a construção de uma nova ordem.

A percepção de que estaremos experimentando mudanças profundas na ordem econômica mundial, nesta última década do século $X X$, está se tornando cada dia mais geral. Os prognósticos, quer pessimistas ou otimistas, são inúmeros, muitos deles resultados de estudos e análises baseados em sofisticados modelos matemáticos e técnicas de projeção ${ }^{3}$. Embora imprecisos - visto que, por mais elaborados que sejam os modelos e técnicas, $o$ imponderável não pode ser calculado - esses estudos são importantes na medida em que sinalizam a exigência de mudanças diante do esgotamento de situações presentes, provendo informações para construção consciente do futuro desejado.

Resultado da confrontação permanente dos agentes sociais, a ordem institucional estabelecida está sujeita a mudanças mais ou menos profundas sob certas circunstâncias. Esses períodos são caracterizados como um tempo de maiores incertezas, desafios, conflitos, ameaças mas, também, esperanças. É nesse contexto que se enquadra a advertência de que "momentos como o $a$ tual são momentos de liberdade; as regras do velho jogo econômico estão superadas e, enquanto se discutem as futuras regras, torna-se possivel, para países marginalizados na partida anterior, tomar lugar à mesa. Abrese para eles uma 'janela de oportunidades' que deve ser aproveitada com rapidez, até o fim do século, o mais tardar" ${ }^{\prime \prime}$. Assim, o domínio do conhecimento científico e da tecnologia aparece como recurso crítico: se não o buscamos rapidamente a janela pode se fechar antes que as oportunidades sejam aproveitadas. $O$ processo já está em curso, e para os que almejam decidir seu próprio destino, não há tempo a perder.

\section{PERSPECTIVAS E OPORTUNIDADES}

Tendo em vista o hiato tecnológico e o baixo nível de investimento em C\&T na América Latina, as perspectivas não podem ser muito boas para esses países. Além disso, as dificuldades econômicas e financeiras, que os países do continente Sul Americano vêm enfrentando ao longo da década de 80, tornam o horizonte ainda mais sombrio.

Para citar o exemplo do Brasil, de 1979 a 1984 o investimento das principais agências do governo, financiadoras de C\&T no País, sofreu uma queda de até $56 \%{ }^{5}$. Entre 1985 e 1987, houve uma recuperação desses investimentos seguida de queda novamente em $1988^{6}$. Sabe-se que, por parte do setor privado, não há investimento em ciência e o investimento em tecnologia é ainda baixo, portanto a avaliação desse cenário não pode ser muito otimista, e pior ainda do que um crescimento baixo ou nulo é o retrocesso no nível de investimento, provocando interrupções de pesquisas com perdas irrecuperáveis e resultante desinvestimento.

Enquanto isso, nos últimos dez anos (1978 a 1987), os três maiores investidores em C\&T, Estados Unidos, Japão e Alemanha Ocidental, mantiveram um firme crescimento de seus investimentos em P\&D. Nesse período, o investimento em P\&D aumentou: no Japão, em 104\%; nos Estados Unidos, em $50 \%$, e na Alemanha Ocidental, em $13 \%$. Se, como sugere Longo, para um dado conjunto de tecnologias correlatas, a criação de novas tecnologias por unidade de tempo é direta-

1. HIGGINS, Winton \& CLEGG, Stewart. Enterprise calculation and manufacturing decline. Trabalho apresentado ao 8th EGOS Colloquium, Antuérpia, julho, 1987.

2. PEREZ, Carlota. "Revoluciones tecnologicas y transformaciones sócio institucionales". In: CRAGNOLINI, Alider (org.). Cuestiones de política científica y tecnologica. Segundo Seminário Jorge Sabato. Madri, 1987, pp. 37-65.

3. RATTNER, Henrique. Estudos do futuro. Introdução à interpretação tecnológica e social. Rio de Janeiro, FGV, 1979.

4.OLIVEIRA,Amaury Porto de. "Surge um novo paradigma industrial". In: Ciência Hoje, vol.9, $\mathrm{n}^{\mathrm{Q}}$ 57, 1989, pp. 18-24.

5. MARCOVITCH, Jacques. "Financiamento de ciência e tecnologia na América Latina". In: Revista de Administração, USP, vol. 23, n² 1, 1988, pp. 5-12.

6. SCHWARTZMAN, Simon. "Ciência e tecnologia na nova República". In: Ciência Hoje, vol. 9, n² 59, 1989, pp.62-69.

7. INTERNATIONAL Science and Technology Data, Update: 1988. Washington, National Science Foundation, 1988. 
mente proporcional à tecnologia existente, dominada e disponível no País ${ }^{8}$, as perspectivas para os países da América Latina não podem ser muito promissoras. Isso significa que o desenvolvimento tecnológico cresce a uma taxa exponencial, e mantidas as relações do nível de investimento entre os fatores, o atraso tecnológico dos países do Terceiro Mundo em relação aos países industrializados tende a aumentar

Todo esse quadro negativo não quer dizer que as oportunidades foram totalmente perdidas. Se todos os fatores permanecerem constantes, certamente o quadro será mantido, mas se a ação consciente e determinada for capaz de mudar alguns fatores, a história pode ser diferente. Além disso, a meta não pode ser apenas uma questão de alcançar os países desenvolvidos, mas, principalmente, o desenvolvimento auto-sustentável adequado às condições e recursos do País.

Visto de outro ângulo, esse mesmo quadro sugere algumas oportunidades. Os Estados Unidos ainda são, de longe, os maiores investidores do mundo em P\&D. Em 1987, o investimento desse País foi quase o dobro do investimento do Japão e da Alemanha Ocidental juntos. No entanto, esses dois países são hoje os maiores concorrentes dos Estados Unidos em áreas de tecnologia de ponta. É evidente que o valor absoluto do investimento não é o determinante maior da eficácia. O esforço concentrado e continuado nas áreas que se quer desenvolver, e/ ou em que se pretende competir, é que aparece como condição necessária para acumular o capital de conhecimento capaz de desencadear o desenvolvimento tecnológico exponencial e auto-sustentável. Para garantir sua primazia, os Estados Unidos são, na verdade, o único país que se vê compelido a competir em todos os campos. Como uma parcela muito grande de seu investimento em P\&D é destinada à defesa, no campo comercial o laís acaba se situando num patamar mais ou menos equivalente ao de seus concorrentes. Por seu turno, sabendo priorizar áreas em que têm vantagens comparativas, esses concorrentes são capazes de ocupar nichos de mercado onde procuram estabelecer seu domínio. Assim, a primeira questão que se coloca é: quais serão nossas oportunidades, dados os recursos humanos e materiais com que podemos contar? Quando tivermos respondido a essa pergunta, será mais fácil definir uma política de desenvolvimento científico e tecnológico sustentável a longo prazo.

Até aqui, a política científica e tecnológica no Brasil tem sido, de um lado, fragmentada, em decorrência de decisões de grupos de burocratas e, marginalmente, de demandas de grupos de ci- entistas; de outro lado, desvinculada da política industrial, dado o modelo de desenvolvimento dependente. A política industrial formulada em 1988 ainda parece distanciada de qualquer política efetiva de C\&T. Como diz Marcovith, essa política é "avançada na escolha de programas setoriais prioritários, tímida no apoio à inovação tecnológica, ousada na liberação das importações, corajosa na intenção de desburocratizar as exportações $e$ incompleta nos instrumentos de implantação"

\section{DESAFIOS E POSSIBILIDADES}

À medida que cresce a competição no mercado internacional, observa-se a tendência à formação de blocos de nações que podem somar vantagens comparativas, assegurando seus próprios mercados e ganhando competitividade no mercado internacional. Não são poucos os que têm alertado para as conseqüências desse novo ordenamento de interesses que se delineia. Contudo, acreditamos que é preciso especular também sobre as origens desse movimento, bem como se ele responde aos desafios que se colocam hoje para a humanidade.

O mundo está, antes de tudo, dividido em nações ricas e nações pobres, com a distância entre uns e outros aumentando a cada dia. Como atesta a Comissão Mundial para o Meio Ambiente e Desenvolvimento, o número de pessoas que passam fome nunca foi tão grande, enquanto a produção aumenta em ritmo acelerado. Ainda que no geral a qualidade de vida haja melhorado, não o foi de forma equilibrada, necessária para assegurar a reprodução do sistema nas condições atuais $^{10}$.

Algumas conseqüências desse desequilíbrio são: a) há os que precisam e não podem consumir e há os que consomem mais do que precisam. Desse lado, parece que a expansão continuada da produção estará condicionada à expansão do mercado consumidor; b) a crença na afluência material como um bem em si mesmo já não é tão inquestionável. $O$ efeito estufa, o esgotamento da camada de ozônio da atmosfera, decorrentes da

8. LONGO, Waldemir Pirró E. "Tecnologia e transferência de tecnologia". In: Informativo do I.N.T., vol. 2, no 23, 1979, pp. 3-19.

9. MARCOVITCH, Jacques. Gestão Tecnológica e a Integração Latino Americana. Trabalho apresentado na XII Reunião Anual da ANPAD, Natal, 1988. Anais. Belo Horizonte, ANPAD, 3 v. v. 1, 1988, pp. 53-67.

10. THE WORLD Commission on Environment and Development. In: Our common future. Oxford. Oxford University Press, 1987. 
poluição e degradação dos recursos naturais, são hoje uma ameaça à vida no planeta. Expandir a produção e consumo nas condições atuais transformaria a ameaça em fato consumado; c) ao mesmo tempo, o próprio progresso dos meios de comunicação propicia maior evidência e visibilidade dos desequilíbrios, aumentando a pressão das camadas marginalizadas por maior participação nos benefícios do progresso material.

Assim, parece que a formação de blocos de interesse não é mais do que uma reação de autodefesa e resposta imediata, mas parcial aos desafios presentes. A solução exige a reconstrução das instituições - econômicas, sociais e políticas - concomitantemente com mudanças estruturais bem mais profundas no sistema produtivo, que deve passar pela substituição de indústrias sujas por indústrias limpas e pelo aproveitamento dos recursos disponíveis de forma que propicie a inclusão e não a exclusão de um maior contingente no mercado consumidor.

Essa reconstrução requer uma definição política da nação tanto quanto um esforço, em quantidade e qualidade, cada vez maior de pesquisa científica e tecnológica.

É diante desse quadro que propomos avaliar o potencial da nova geração de empresários, nas indústrias novas, para um adequado comportamento como agentes catalisadores no esforço de desenvolvimento tecnológico autóctone e na remodelagem da nova ordem institucional.

\section{OBJETO DA PESQUISA}

A análise baseia-se numa pequena amostra de empresários no Estado de Minas Gerais. Essa amostra compreende 13 pequenas e médias empresas, 12 do setor de eletroeletrônica e uma empresa mecânica. A empresa mais antiga foi fundada em 1961 e a mais nova em 1984, sendo que apenas três foram criadas na década de 60 , quatro foram criadas na década de 70 e as outras seis na década de 80 . A análise não pretende ser conclusiva, mas, antes, identificar possibilidades, ou mesmo levantar questões que possam orientar na busca de respostas para os problemas presentes.

A ação do empreendedor vem sendo objeto de interesse crescente na literatura administrativa. Essa literatura enfatiza o papel de inovador do empreendedor ${ }^{11}$ no que se aproxima do conceito schumpeteriano de empresário. Estende o conceito de empreendedor para designar o empregado inovador, i.e., capaz de vislumbrar novas oportunidades e iniciar novos negócios dentro das grandes empresas. Esse empregado criativo é chamado intra-empreendedor e, na prática, é tratado como um tipo especial de empreendedor a quem se devem dar espaço e estímulo para colocar suas idéias a serviço da organização. Esse conceito serve pouco aos propósitos de nossa análise, pois não oferece um referencial teórico que possibilite a análise da prática social do empresário. Para os objetivos dessa análise, vamos caracterizar o empresário como agente social, na direção de um empreendimento, e tanto pode ser um inovador quanto um conservador.

O empresário brasileiro não se apresenta como um grupo homogêneo, mas um traço bem marcante da elite empresarial tradicional do país é o conservadorismo $^{12}$. Outras categorias de empresários podem ser identificadas pelas características do mercado de suas empresas e sua ação na direção da empresa ${ }^{13}$. As questões propostas são: Quem é o empresário nas novas indústrias? Qual o compromisso desses empresários com o desenvolvimento de uma tecnologia autóctone? Quais as possibilidades de ação desse grupo na reconstrução da ordem institucional? A pesquisa foi feita por meio de entrevistas buscando dados objetivos referentes à organização da empresa e dados subjetivos referentes à percepção que esses empresários têm da organização e do ambiente.

\section{AS EMPRESAS E OS EMPRESÁRIOS}

Por se tratar de empresas de pequeno e médio porte, a estrutura dessas empresas é bastante simples. Todas elas foram criadas por dois ou mais sócios, motivados pela identificação de um mercado para um produto que eles podiam fornecer. Em todos os casos, pelo menos um dos sócios detinha a tecnologia do produto, copiada ou modificada. Hoje quase todas já produzem de dois a cinco produtos, algumas na mesma linha, outras buscando diversificar a linha de produtos. Das treze empresas, nove estão localizadas na área metropolitana de Belo Horizonte e as outras quatro, no interior do Estado. A maioria das empresas de Belo Horizonte (sete entre as nove) tem como maior cliente a TELEMIG ou a CEMIG, o que as coloca numa situação de forte dependência e vulnerabilidade a qualquer mudança num

11. SANTOS, Sílvio Aparecido dos \& PEREIRA, Heitor José. Intra-empreendedores $e$ inovação tecnológica nas empresas brasileiras. Trabalho apresentado na XII Reunião Anual da ANPAD, Natal, set., 1988.

12. BOSCHI, Renato Raul. Elites industriais e democracia. Rio de Janeiro, Graal, 1979.

13. CARDOSO, Fernando Henrique. Empresário industrial e desenvolvimento econômico no Brasil. São Paulo, Difel, 1964. 
ambiente em que elas têm muito pouca ou nenhuma influência. A relação das linhas de produtos das empresas está no Anexo 1.

Quase sempre a direção da empresa é dividida entre os sócios. Só em duas empresas é que apenas um dos sócios é o gerente. Nesses casos, profissionais são contratados para cargos de direção que dividem com o sócio gerente. Em uma empresa de cinco sócios, estes não só dividem a direção como fazem um rodízio nas funções de gerência. Com isso, eles pretendem ter uma experiência em todas as áreas (finanças, administração, mercadologia, produção e P\&D), ter uma visão global da empresa, além de dividir os encargos de maneira mais equitativa, pois, na opinião deles, algumas funções são mais pesadas do que outras. A experiência tem dado certo, a empresa tem uma história de 12 anos de crescimento. Como nos disse um diretor, eles começaram os cinco numa garagem, fazendo de tudo; hoje estão instalados numa área grande, têm 139 empregados e continuam se expandindo.

O perfil da estrutura de mão-de-obra dessas empresas, por ocupação e por nível de formação, está resumido no quadro 1.

Em média, as empresas têm $61 \%$ do pessoal ocupados na produção, $29 \%$ ocupados em atividades de apoio e $10 \%$, em atividades de P\&D. A variação é bem grande, contudo é bastante influenciada por três casos que se distanciam da média da amostra. Em dois casos, o tamanho da empresa (medido pelo número de empregados) pode ser um fator diferenciador na distribuição ocupacional da mão-de-obra.

Tanto na maior empresa (357 empregados) quanto na menor (18 empregados), há uma proporçăo muito grande de pessoal de apoio. O terceiro caso é o da empresa mecânica que se diferencia por ter uma parcela de pessoal ocupada na produção proporcionalmente bem mais alta do que as outras empresas, do setor eletroeletrônico.

Com relação à formação, observamos que, em média, $11 \%$ do pessoal têm o terceiro grau; $19 \%$, o

\section{QUADRO I: Estrutura da mão de obra}

\begin{tabular}{lrrr|rrr}
\hline \multicolumn{3}{c}{ OCUPAÇÃO } & \multicolumn{3}{c}{ FORMAÇĀO } \\
\hline & P.Prod. & P.Apoio & P\&D & N.S. & N.T. & N.P. \\
& & & & & & \\
Média & 61 & 29 & 10 & 11 & 19 & 70 \\
D.P. & 15 & 13 & 05 & 06 & 12 & 13 \\
Var. & 209 & 146 & 22 & 34 & 133 & 154 \\
Amplit. & 58 & 33 & 14 & 19 & 30 & 41 \\
\hline
\end{tabular}

FIGURA 1: Distribuição de pessoal por ocupação

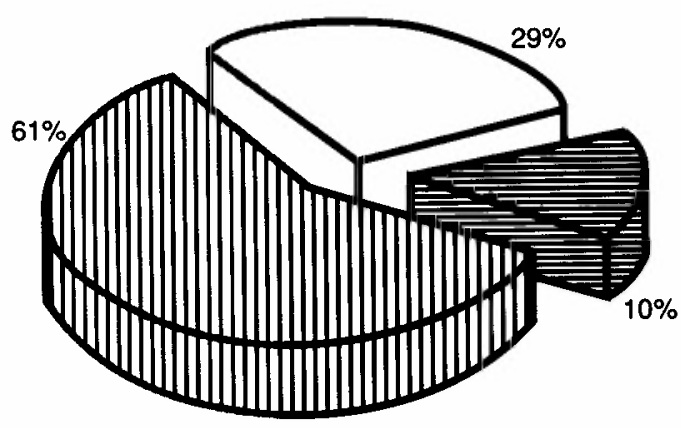

IIIIIIIfPessoal de Produçáo Pessoal de P\&D $\square$ Pessoal de Apoio

FIGURA 2: Distribuição de pessoal por nivel de formação

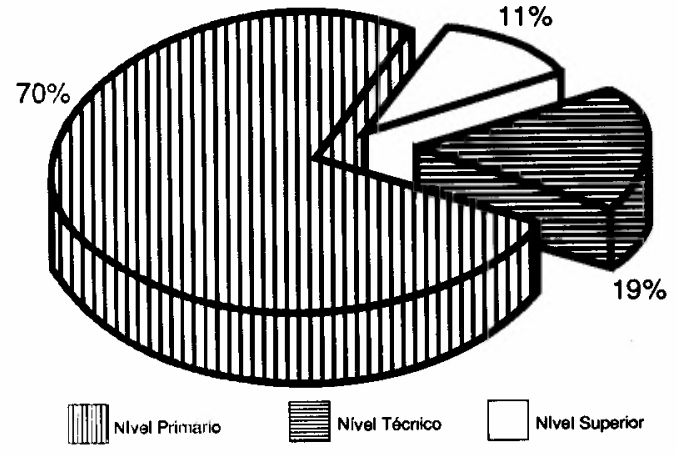

segundo grau e $70 \%$, apenas o primeiro grau, com ou sem algum treinamento profissional. Nesse caso também, a variação é bem grande, indicando uma amostra pouco homogênea. As figuras 1 e 2 mostram de forma gráfica a distribuição média de pessoal por ocupação e por nível de formação respectivamente.

Todas as empresas têm uma unidade de P\&D, mas só em duas existe o cargo de pesquisador. $O$ mais comum são os cargos de engenheiro e de técnico, que correspondem à formação das pessoas ocupadas em $\mathrm{P} \& \mathrm{D}$. O pessoal de nível mais alto nas unidades de P\&D dessas empresas são engenheiros graduados. Vale observar que não encontramos nenhum pós-graduado, nem mesmo em nível de mestrado; falta-lhes portanto, uma formação e treinamento em pesquisa. Na realidade, as atividades dessas empresas estão limitadas a desenvolvimento, apenas duas delas têm um plano concreto para iniciar atividades de pesquisa. O que não podemos deixar de indagar é 
se elas têm condição de realizar pesquisa sem um esforço para qualificação adequada de pessoal. $\mathrm{Na}$ maioria das vezes, o pessoal de nível técnico e superior é recrutado nas instituições de ensino, quase sempre recém-formados e, na opinião dos empresários, não tem sido fácil recrutar profissionais competentes nessa área. É pouco provável que alguns anos de treinamento em desenvolvimento de produtos sejam suficientes para preparar um pesquisador, portanto, para formar uma equipe habilitada para executar pesquisas autonomamente. Assim, as alternativas que aparecem para essas empresas se engajarem em atividades de pesquisa são: a contratação de profissionais com formação e treinamento em pesquisa, ou a contratação de pesquisas com universidades e/ou institutos de pesquisa, através de convênios para execução conjunta de projeto, que proporcione a oportunidade de aprendizado e treinamento de seu próprio pessoal.

Dentre os treze empresários entrevistados, apenas cinco já tiveram experiência de pesquisa com universidades ou institutos de pesquisa, mas todos, exceto um, acreditam que o intercâmbio com universidades pode contribuir positivamente para o desenvolvimento tecnológico. Várias formas de cooperação foram sugeridas, mas a principal demanda é pela utilização dos laboratórios e equipamentos das universidades. Imaginam que essa utilização pode se dar através de estágios, trabalho conjunto de equipes da universidade $e$ da empresa, arrendamento de equipamentos para as empresas, ou que a universidade poderia desenvolver tecnologia para ser repassada pronta para as empresas. O grupo vê também dificuldade para uma colaboração efetiva entre universidade e empresa no Brasil. Entre as dificuldades apontadas estão: os preconceitos de ambas as partes, as diferenças de objetivos e, principalmente, problemas de comunicação que inviabilizam o diálogo.

Os projetos de pesquisa-desenvolvimento são definidos pela alta administração, sendo que em algumas empresas o gerente de P\&D participa da decisão. A centralização das decisões de inovações e desenvolvimento tecnológico não surpreende. Ao contrário, diríamos mesmo que parece normal ou natural. As organizações brasileiras caracterizam-se por um modelo de decisão geralmente centralizado ${ }^{14}$; nas pequenas e médias empresas não há, geralmente, escala de especialização e hierarquia que induza à descentralização de decisões; além do mais, as empresas pesquisadas são dirigidas por pelo menos um especialista - engenheiro - para quem o conhecimento da tecnologia é a razão mesma da sua empresa.
Perguntados sobre que critérios são utilizados prioritariamente na escolha de projetos de P\&D, os empresários foram unânimes em citar "oportunidade de mercado" como fator decisivo. A preocupação maior está em aproveitar as oportunidades para ampliar e diversificar o mercado nos limites de seu domínio tecnológico.

Percebe-se que a postura desses empresários aproxima suas empresas da categoria de "analisadoras" sugerida por Miles \& Snow ${ }^{15}$. Segundo esses autores, o processo adaptativo das organizações é resultado da percepção que seus dirigentes têm das condições ambientais e de como eles respondem a essas condições. O processo é entendido a partir da avaliação de como as organizações resolvem problemas de ordem empresarial, i.e., fazem as escolhas: de seu território, em termos de produto-mercado; de engenharia; de tecnologia; e de administração. Tais escolhas envolvem, de um lado, a seleção de áreas para inovações futuras, e de outro, a racionalização da estrutura e processos. A análise de diferentes organizações com base no paradigma proposto permitiu aos autores identificarem quatro categorias de organizações: as organizações "defensoras", que operam produtos-mercados restritos, tecnologias e métodos operacionais tradicionais e dão grande ênfase à melhoria da eficiência interna; as organizações "reatoras" que percebem mudanças e incertezas no ambiente, mas que têm dificuldade de adaptar-se por causa da inconsistência entre a demanda do ambiente e a estrutura e processos internos; as organizações "analisadoras" que operam, ao mesmo tempo, num mercado estável e num mercado mutável, e procuram seguir de perto seus concorrentes, e por fim, as organizações "prospectoras" que buscam continuamente novas oportunidades de mercado, estão atentas às tendências emergentes, portam-se como empresas criadoras ou agentes de mudanças.

Uma descrição dessas quatro categorias foi apresentada aos empresários e a cada um foi perguntado em que categoria classificava sua empresa. Ainda que nenhuma empresa tenha projetado um produto efetivamente novo, no sentido de mudar o padrão de consumo ou de criar novas necessidades, ou um produto tecnicamente revolucionário, oito entre os treze empresários entrevistados classificaram suas empresas como

14. RODRIGUES, Indiana P. F. Patterns of influence in management decision making. Tese de doutorado, University of Bradford, 1986.

15. MILES, Raymond E. \& SNOW, Charles C. Organizational strategy, structure, and process. Tokyo, McGraw-Hill, Kogakusha, 1978. 
prospectoras. Uma leitura que podemos fazer desse dado é que o ideal desses empresários é ter uma empresa inovadora, tecnologicamente avançada, para assumir liderança em seu setor.

Dadas suas limitações, que englobam tanto a escassez de recursos financeiros, humanos, de informação tecnológica e mercadológica, quanto as incertezas decorrentes da instabilidade econômica e política (que de resto são limitações do país como um todo), eles não vêem com nitidez o caminho que os conduziria à meta desejada. Ainda assim, mantêm vivo seu ideal. Dos outros cinco empresários de nossa amostra, dois classificaram suas empresas como analisadoras; um classificou como defensora; um como reatora e um outro acha que sua empresa não se enquadra em nenhuma das categorias descritas.

Cinco empresas já obtiveram patente de algum produto; porém, mesmo aqueles empresários que têm algum produto patenteado se mostram bastante céticos com relação ao sistema de patentes. Na percepção da maioria dos empresários, o processo de registro de patente é complexo, custoso e não oferece o retorno esperado, na medida em que não exclui a entrada no mercado de produtos concorrentes com características diferenciais mínimas. Tal percepção sugere que uma avaliação de custo-benefício de patentes só será positiva se a tecnologia incorporada ao produto e/ou processo colocar a empresa numa posição de vanguarda, o que não é o caso em nenhuma das empresas pesquisadas.

Incentivo fiscal foi, de longe, o mais citado fator de estímulo ao investimento em P\&D. A reserva de mercado é considerada boa, mas há forte restrição quanto à forma como vem sendo praticada. Não sugerem, porém, uma alternativa concreta de aplicação da reserva de mercado. $O$ fator inibidor de investimento em P\&D mais lembrado foi a instabilidade econômica. Houve, porém, quem mencionasse também a dificuldade de importação de livros, protótipos etc., por conseguinte, de atualização de literatura técnica e outros meios de acesso à tecnologia de ponta. Cabe aqui observar que tecnologia não é objeto de publicação; afinal, o segredo continua sendo a alma do negócio. Se a dificuldade de acesso a publicações atualizadas é um fato concreto, não é menos verdade que avanços do conhecimento veiculados na literatura técnico-científica só terão utilidade, do ponto de vista comercial, se a empresa estiver capacitada para desenvolver tecnologia a partir desse conhecimento. A baixa demanda desse tipo de recurso parece ser reflexo da estrutura de $P \& D$, ainda incipiente, do conjunto das empresas pesquisadas. Quando perguntamos que recursos (financeiros, humanos ou físicos) consideravam mais importantes para efetivação da atividade de $P \& D$ na empresa, a maioria dos empresários deu prioridade aos recursos financeiros, argumentando que, havendo recursos financeiros, o problema dos outros recursos seria resolvido. Visto que atestaram ser difícil recrutar profissionais competentes, o que parecem perceber como problemático é sua capacidade de remunerar competência e não a escassez dessa mão-de-obra no mercado de trabalho. Como a formação de um pesquisador requer alguns anos de estudo e treinamento, é pouco provável que o simples aporte de recursos financeiros seja capaz de resolver o problema de oferta dessa mão-deobra a curto prazo. A percepção, um tanto contraditória, sugere que não há, por parte da maioria desses empresários, um conhecimento muito claro do profissional de que precisam para desenvolver atividades de $P \& D$, ou da realidade do mercado de trabalho na área.

A visão desses empresários, no que diz respeito às políticas de $C \& T$ praticadas no país, também não é muito clara. De um modo geral, não têm opinião formada sobre a política de C\&T para o país como um todo. Quanto à política para seu setor específico, as opiniões mais correntes são de que não atende à pequena e média empresa e que não é ruim, mas tem sido mal aplicada.

\section{A PAISAGEM VISTA DE NOSSA JANELA}

Uma característica que parece comum aos empresários de nossa amostra é o interesse pela tecnologia de produto que eles vêem como recurso estratégico no seu ramo de negócio. Embora não definam com muita clareza um plano de desenvolvimento tecnológico, têm consciência da importância de acompanhar o progresso técnico, procurando desenvolver seus produtos para atenderem à demanda do mercado. $O$ ideal de uma empresa independente e competitiva aparece, então, como um traço bem marcante, e, na medida em que as empresas crescem, surge também a preocupação com técnicas gerenciais tendo como meta uma administração moderna e eficaz.

Por certo que essas são algumas características que diferenciam esses empresários do empresário brasileiro tradicional, conservador, autoritário, muito mais preocupado em assegurar mercados cativos do que em ter uma empresa competitiva, $\mathrm{e}$ interessado em pagar por uma tecnologia incorporada ao produto ou processo antes que em ter o conhecimento e domínio da tecnologia que utiliza.

Essas diferenças indicam que as novas indústrias podem estar criando espaço para a emergên- 
cia de um novo tipo de empresário. Embora nossa amostra seja muito pequena e não nos permita fazer generalizações, não podemos, por isso, subestimar os indicadores que apontam características bem nítidas desse grupo de novos empresários. Trata-se de um grupo jovem (a maioria na faixa dos trinta anos) cujo perfil é marcado pelo ideal de independência e que valoriza o domínio da tecnologia e a eficiência administrativa como instrumento de competição.

A avaliação que fazemos, com base nas características que identificamos no grupo, é que essa nova geração de empresários tem potencial para iniciar novas práticas administrativas e de negócios no País. Contudo, mesmo supondo que os novos setores industriais estão em expansão e que o perfil de empresário encontrado no segmento pesquisado pode ser representativo de uma população bem maior e crescente, essa avaliação nos leva a indagar se serão capazes de institucionalizar essas novas práticas, ou seja, de liderar mudanças de atitude e de comportamento. Qualquer mudança na ordem estabelecida, por necessidade, contraria interesses e ameaça o status dos grupos que a sustentam e dela se beneficiam. Implica na reestruturação das relações de poder $e$, obviamente, a capacidade de influência de um grupo depende de sua forma de inserção na sociedade e de sua força política vis-à-vis a força política de outros segmentos.

$\mathrm{Na}$ medida em que esses empresários são atores dispersos no universo do empresariado brasileiro e não encontramos nenhum indicador de qualquer ação articulada que os caracterize como um grupo, a probabilidade de desempenharem o papel de agentes de mudança pode não ser muito alta. Mas a história está sendo escrita a cada momento e o simples fato de que existem pessoas vivenciando novas práticas sociais estimula a imaginação e reforça a expectativa de que um certo realinhamento estrutural pode estar em curso ${ }^{16}$.

16. Este artigo foi apresentado, em versão preliminar, no XIV Simpósio Nacional de Pesquisa de Administração em Ciência e Tecnologia, realizado em Curitiba, outubro de 1989.

ABSTRACT: Data concerning the structuring of activities and of manpower, of a group of manufacturing organizations, as well as the entrepreneurs' perception of their environment, are used to assess the ability of a new generation of entrepreneurs to pull technological innovation. It is suggested that the economic changes underway in these last decades of the XX century are not detached from transformations in the social and political spheres. Scientific and technological know-

\section{ANEXO 1}

\section{EMPRESA 01}

PRODUTOS: Equipamentos para laboratório; análise clínica; PABX

EMPRESA 02

PRODUTOS: Controlador programável; balança eletrônica para transportadora; instrumentação para medida de densidade e nível; sistema de comunicação industrial.

EMPRESA 03

PRODUTOS: Equipamentos de rádio comunicação para longa e curta distância.

EMPRESA 04

PRODUTOS: Circuito impresso; etiquetas; plaquetas e impressões em painéis.

EMPRESA 05

PRODUTOS: Terminais de vídeo; concentradores de terminais.

EMPRESA 06

PRODUTOS: Sistemas de telesupervisão; estabilizadores; no break.

EMPRESA 07

PRODUTOS: Central telefônica - juntores analógicos e digitais.

EMPRESA 08

PRODUTOS: Relês.

EMPRESA 09

PRODUTOS: Telefone para registrador de tempo; equipamento para transmissão e telefonia; equipamento para automação de central eletromecânica; instrumentos para telefonia.

EMPRESA 10

PRODUTOS: Receptor e transmissor de televisão com mais 82 possibilidades de combinação.

EMPRESA 11

PRODUTOS: Antena telescópica; antena parabólica.

EMPRESA 12

PRODUTOS: Controlador de demanda de energia elétrica; no break; retificadores industriais.

EMPRESA 13

PRODUTOS: Micros profissionais de 16 bits; terminais de vídeo.

ledge are understood as critical resources which can only be pursued through the conscious will of social actors. Third World countries do not need to undergo the paths of the developed countries, but to search for a self sustained development that must cut out for the natural resources and social milieu in each case.

KEY TERMS: Technological development, entrepreneur, technology, environment, entrepreneurship. 